EPJ Web of Conferences 78, 01006 (2014)

DOI: $10.1051 /$ epjconf / 20147801006

(C) Owned by the authors, published by EDP Sciences, 2014

\title{
Eugene P. Wigner - in the light of unexpected events
}

\author{
L. Koblinger ${ }^{a}$ \\ Hungarian Atomic Energy Authority, P.O.Box 676, H-1539 Budapest, Hungary
}

\begin{abstract}
In the first part of the paper, Wigner's humane attitude is overviewed based on the author's personal impressions and on selected quotations from Wigner and his contemporaries. The second part briefly summarizes Wigner's contribution to the development of nuclear science and technology.
\end{abstract}

\section{Introduction}

It should first be mentioned that this presentation was not included in the original programme of the symposium. Briefly, to everybody's dismay one of the distinguished lecturers broke his femur during the Opening Ceremony. This was the first of the 'unexpected events' I ventured to mention in the title. The second one immediately followed: the organizers asked me whether I'd be prepared to fill the gap with anything that might somehow be related to the theme of the meeting. After a couple of hours' hesitation I accepted (this being unexpected event number three). I was highly honoured by the invitation and assumed that a somewhat informal talk might be tolerable since it would be impossible for me to compile a really worthwhile lecture during the one and a half days at my disposal.

\section{Meeting the name Wigner}

I was still at school when I first heard the name Wigner. This was in 1963 and he was one of the three physicists who had been awarded a Nobel Prize. (Naturally, the announcement that I heard was in the Hungarian style: in other words, Wigner Jenó.) Needless to say and bearing in mind that he was born and had grown up in Budapest - this great honour was widely discussed in the Hungarian media. The articles, depending on the profile of the particular journal, discussed at various depths his scientific merits. Even though it was by no means easy to follow the rather sophisticated descriptions given in the more-scientific papers, it was abundantly clear that despite his having made a tremendous contribution to the development of nuclear technology, the focal point of his activities was theoretical physics. The Nobel Prize Committee had made the award to Eugene Paul Wigner "for his contribution to the theory of the atomic nucleus and elementary particles, first of all for the discovery and application of the fundamental symmetry principles". Dealing with nuclear questions was just an intermezzo in his life, despite it being an immensely important contribution to the

\footnotetext{
a e-mail: koblac55@gmail.com
} 


\section{EPJ Web of Conferences}

history of mankind. Apart from the scientific result there was another aspect of his life which was strongly emphasized in virtually all of the sources: viz. Professor Wigner's legendary kind nature, and his extreme politeness and modesty. In 1980, when I had the pleasure of a short visit to the Oak Ridge National Laboratory where Wigner had - for a short time - been the director, I was introduced to several of his erstwhile contemporaries. When they became aware that I was Hungarian, they all started to praise Wigner - this 'absolutely charming' gentleman.

\section{Simple politeness or something more?}

Let me continue with this aspect: Wigner's legendary politeness. In 1976, for the first time since his emigration, he paid a visit to Hungary. It gave me immense pleasure to attend one of his lectures and to watch an interview with him on Hungarian TV. The latter could only be described as a unique experience: at certain points I couldn't help laughing as it was such an enjoyment to witness the amusing contrast between the enthusiasm of the reporter and the modest attitude of this really great man, Wigner. I should like to illustrate this (hoping that my memory serves me correctly) with a couple of examples. The interview tended to concentrate on his nuclear activities since obviously many of the viewers could hardly follow a discussion on theoretical physics, so the reporter asked him about the highly surprising event of the first chain reaction. And then came Wigner's well-modulated answer: "Well, if you don't mind my saying so, it wasn't really such a great surprise for us. You see, Fermi had calculated in advance that when the control rods were gradually pulled out there would be a certain point at which the chain reaction should start up."

The second example that I'd like to refer to was when the reporter mentioned that epic moment when the atomic age began. Wigner again cooled him down saying "I'm really not quite sure what you mean by 'the atomic age.' " And the one I liked most was when the reporter assumed that the realization of nuclear fission might have been the greatest invention in human history - and Wigner's comment was again modest but strictly to the point: 'I'm not quite sure I can agree with that. Possibly the invention of the steam engine might have been more important." At the end of this TV programme I found myself speculating that although all Wigner's responses were polite and modest there was a great deal of irony embedded. Even though politeness and modesty were integral characteristics of Wigner, they were deliberately used by him to pack in sometimes very ironic messages and - if you like - warnings. In the examples given above, he was warning the reporter to distinguish between surprises and scientifically-based expectations, he was suggesting that such bombastic phrases as 'atomic age' should be avoided; moreover, nor should the scientific importance of any single invention be over-estimated or removed from the sequence of important discoveries.

I should like to support the validity of this observation with two other illustrations. Once upon a time, another Hungarian physicist, Valentine Telegdi (Telegdi Bálint), was at odds with the editors of the Physical Review and since that journal was a publication of the American Physical Society he turned to Wigner for help. And Wigner's answer [1]: "Unfortunately, there's nothing I can do for you at the American Physical Society, I'm only its president." is again ironic, criticizing those societies where the president is a figurehead, a position preserved for high ranking people, without any real functions or power. And, turning back to the Nobel Prize, Wigner commented on the news in his usual modest way, stating that he'd never expected it, and he then added somewhat sarcastically "I never expected to get my name in the newspapers without doing something wicked". I guess the ironic criticism of the media where the interesting event is much more a crime than an achievement in science is obvious. 
Wigner 111 - Colourful \& Deep Scientific Symposium

\section{Wigner's path to nuclear issues}

Possibly the most appropriate starting point is when the talented young Wigner was enrolled in the Lutheran Secondary School in Budapest. Incidentally, Wigner never failed to mention the invaluable role of László Rátz, his first-rate mathematics teacher, who played an important part in turning his interest towards mathematics and natural sciences. Once he'd finished school, Wigner decided to continue his studies in the field of physics; however, his father convinced him that at the time, there was no need for more than 3 or 4 physicists in Hungary, so Wigner decided to turn to chemical engineering - first in Budapest and later in Berlin. On completing his university years abroad, he returned to Hungary to work in a tannery - although nowadays, to many of us, it may sound unexpected. (Wigner practically never mentioned that the tannery was owned by his father!). Much less unexpected is that after a couple of months he was invited back to Germany - to the Kaiser Wilhelm Institute for Physical Chemistry and Electrochemistry. He worked in Berlin as an assistant professor in physics and later was given the privilege to go to Göttingen where he could further advance his mathematics knowledge as an assistant to David Hilbert. In 1930 he moved to Princeton which became his base for the rest of his life. After leaving Hungary (and routine chemical engineering) his activities reverted to theoretical physics. Another unexpected (or possibly not so unexpected for far-seeing people like Wigner) event, however - the outbreak and escalation of World War II - led to a new turn in his career.

In this context, instead of saying, pathetically, something like: 'understanding the duty to save democracy, or freedom, or even human civilization', he simply commented later in a typically modest and ironic Wignerian style: "Thoughts of being murdered focus your mind wonderfully." His first contribution to the atomic bomb development was to translate from German into English the famous Einstein-Szilárd letter to President Roosevelt. (It may be worth mentioning here that though throughout his life he never lost his Hungarian accent, he was quite famous for his very precise use of English scientific and technical terminology.) Later, he was one of the great physicists who joined the Manhattan Project and one of the major contributors to the realization of the first chain reaction, a co-worker of Fermi at the construction of the Chicago reactor (or 'pile', to use the original wording). The main purpose here was the experimental demonstration of the possibility and feasibility of the nuclear fission chain reaction. In view of this, the Chicago pile had neither cooling nor shielding.

The next stage was to construct the Hanford reactor for plutonium production, i.e. for direct military use, for building nuclear weapons. At Hanford, one of the first exciting questions was the selection of the appropriate cooling material. According to Rhodes [2]: "Helium, which absorbed no neutrons at all, was the coolant of choice at first, but Hungarian theoretical physicist Eugene Wigner, trained as an engineer, held out for water despite its neutron-scavenging propensities because it would be simpler and thus faster to engineer." Almost certainly this was the first time in nuclear history that engineering factors took priority over the pure physics considerations. No wonder that his long-time colleague Alvin M. Weinberg called Wigner the 'first nuclear reactor engineer'. The dominant role of Wigner in the early development of nuclear science and technology, especially at Hanford, can be illustrated by another quotation [3]: "Wigner and his team had completed a task of almost unbelievable proportions, perhaps without equal in the annals of science and engineering."

The engineering work at Hanford was basically governed by staff of the DuPont Company. It is worth mentioning how Wigner remembered [4] his own and his group's contribution: "When DuPont drawings came, it was very important - with due respect to DuPont - that we reviewed them." Special attention should be given to Wigner's polite insertion: 'with 


\section{EPJ Web of Conferences}

due respect to DuPont', though Weinberg's memory [5] is less polite, nevertheless, perhaps more realistic: "I think DuPont never quite trusted any of Wigner's group... To be blunt, Wigner didn 't trust DuPont either." There is another element in the Wigner sentence above, 'When DuPont drawings came', which is worth further discussion. I am sure there were only a limited number of theoretical physicists there who could easily understand a technical drawing and, moreover, who could quickly reconstruct in their minds a three-dimensional picture of something from the three projections on paper. Searching the Internet I found another curious comment [6] emphasizing the importance of Wigner's chemical engineering studies: ". . . theoretical physicists usually think in terms of very large scale entities and events, or in terms of very small scale entities or events. Chemical engineers think of intermediate, human scale objects and events." I'm unable to judge whether the scale of entities really had a crucial role in the Manhattan Project but it's beyond question that both human beings and nuclear reactors are much larger than elementary particles and much smaller than galaxies.

Anyhow, his extensive knowledge of both engineering and theoretical physics made Wigner a key figure at the dawn of the development of nuclear techniques. As Seitz [3] summarizes in a concise manner: "Wigner's personal imprint was on every aspect of the design." The original lecture that I was invited to replace would have been entitled 'Wigner, the first and best nuclear engineer'. I very much hope that the original - Weinberg's - qualification 'the first' is obvious for those who know the whole history. But what about 'the best'? I'm well aware that there have been excellent nuclear engineers since his time; moreover, I very much hope that there will be in the future. However, I find it hard to believe that there will ever be another individual with such a comprehensive knowledge of all the theoretical aspects. And it's for this reason that Wigner can be called 'the best' nuclear engineer.

\section{Our nuclear heritage from Wigner}

Finally, apart from the historical aspects of his work, at this point I should like to consider: What are the results he left for our generation, and what is our heritage from his work on our everyday lives? Without a doubt, people who are studying nuclear engineering or who are working in any nuclear engineering field will frequently come across Wigner's name and his results. They will learn about the Wigner effect (and the Wigner energy related to it), or the discomposition effect, the displacement of atoms in a solid caused by neutron irradiation. (This effect had an indirect role in the Windscale fire, in 1957, one of the early nuclear accidents that even nowadays is still in the news.) During analysis of neutron cross sections and in calculating resonances, it is unavoidable that there will be the need to use the BreitWigner formula. Even more importantly than those inventions that might be known only by experts: "Wigner designed a water-cooled, water- moderated converter ... making him the grandfather of today's research reactors, naval reactors, and nuclear power plants" [7]. And since most electricity-generating reactors are of such construction, Wigner's invention has a vast influence on the everyday life of large populations in many countries, including his native land, Hungary. 


\section{Wigner 111 - Colourful \& Deep Scientific Symposium}

\section{References}

[1] G. Marx: Beszélgetés marslakókkal (Conversation with Martians - in Hungarian). (OOKPress, Veszprém, 1992)

[2] R. Rhodes: Hanford and History. B Reactor 60th Anniversary Banquet Address (2004). http://www.b-reactor.org/hanford_history_rhodes.htm

[3] F. Seitz, E. Vogt and A. M. Weinberg: Eugene Paul Wigner. Biographical Memoirs 74 (The National Academies Press, Washington DC, 1998)

[4] J. Mehra: Eugene Paul Wigner: A Biographical Sketch, in: The Collected Works of Eugene Paul Wigner 1 (Springer-Verlag, Berlin, Heidelberg, New York, 1993)

[5] A.M. Weinberg: The First Nuclear Era: The Life and Times of a Technological Fixer (American Institute of Physics, New York, 1994)

[6] C. Barton: Fermi's folly, Wigner's wisdom. In: Energy from Thorium (2008). http://energyfromthorium.com/2008/10/18/fermis-folly-wigners-wisdom

[7] Nuclear Power and Research Reactors. From Manhattan Project To Electricity Production. ORNL Review 36 (Oak Ridge National Laboratory, 2003). http://web.ornl.gov/info/ornlreview/v36_1_03/article_01.shtml 
